\title{
Rising trends and changed indications of caesarean sections in Sikkim, India: cause for concern?
}

\author{
Hafizur Rahman ${ }^{1 *}$, Dipika Pradhan ${ }^{2}$
}

\begin{abstract}
${ }^{1}$ Department of Obstetrics and Gynaecology, Sikkim Manipal Institute of Medical Sciences, Gangtok, India
${ }^{2}$ Department of Obstetrics and Gynaecology, STNM Hospital, Gangtok Sikkim, India
\end{abstract}

Received: 21 March 2016

Accepted: 23 April 2016

\section{*Correspondence:}

Dr. Hafizur Rahman,

E-mail: hafizezzy@gmail.com

Copyright: () the author(s), publisher and licensee Medip Academy. This is an open-access article distributed under the terms of the Creative Commons Attribution Non-Commercial License, which permits unrestricted non-commercial use, distribution, and reproduction in any medium, provided the original work is properly cited.

\begin{abstract}
Background: Caesarean sections (CS) are performed when vaginal delivery is found unsafe for the fetus and/ or mother. CS may be associated with many short and long term complications. World health organization determines that CS rate should within five and fifteen percent and no additional benefit is gained to the neonates or mothers when the rate exceeds the highest level. The rate of CS is above the WHO determined mark for many developed and developing Asian countries, and it is increasing over the time. This situation of overburdened caesarean rates needs special attention. The scenario of the states with respect to the CS and the complications that are responsible for the caesarean section is a matter that has to be given some insight into. The aim of this study was to investigate and compare the rate and indications for CS in the early 2000s as compared to early 2010s.

Methods: It was a retrospective cohort study. Data were collected from original obstetrical records in different hospitals of Sikkim in 2001 and 2011. Both groups were compared for CS rate and trends of indications of CS.

Results: The results revealed that in the year 2001, the rate of CS at Sikkim was $10.1 \%$ and in the year 2011 it rose to 19.4\%. The main indications for an elective cesarean in 2001 were previous CS (24.1\%) and Cephalopelvic disproportions (16.5\%). In the year 2011 along with previous CS (31.3\%) another dominant indication for an elective cesarean was a maternal request (29\%) for fear of childbirth without any co-existing medical indication. Anticipated fetal compromise remained the most common indications for urgent and emergency CS during both the study period. Conclusions: CS rate almost doubled over the last decade in Sikkim with a significant contributory factor in increasing proportion of CS were cesarean sections on maternal request without any co-existing medical or obstetric indication.
\end{abstract}

Keywords: CS, Changing trends, Indication, Maternal request

\section{INTRODUCTION}

Cesarean section (CS) is an operative procedure whereby the fetuses are delivered through an incision on abdominal and uterine wall after 28 week of pregnancy. Cesarean sections are categorized as elective and emergency. ${ }^{1}$ Elective CS is performed according to a prenatal indication and at a time to suit the patient and the maternity team.

Urgent CS are performed at labour, most commonly due to failure to progress or an anticipated fetal compromise, which is not immediately life threatening. Emergency CS are performed when there is an immediate threat to the woman and/or to fetus. ${ }^{1}$

CS may be associated with short term and long term risks. Short-term maternal risks associated with CS include bleeding, injury of urogenital or gastrointestinal organs, postoperative infection and an increased risk for deep venous thrombosis. ${ }^{1,2}$ In long term there are increased risks of severe bleeding following uteroplacental complications such as placenta previa and placenta accreta in subsequent pregnancies. ${ }^{1,2}$ Short-term 
risks for the fetus and newborn include injury of the presenting fetal part and neonatal respiratory distress including transient tachypnea and persistent pulmonary hypertension. $^{3}$

The World Health Organization (WHO) published guidelines regarding caesarean rates in 1985, which was revised in $1994 .{ }^{4,5}$ The guidelines determines that the proportion of caesarean births should range 5-15\%. According to WHO no additional benefit gained to the neonates or the mothers when the rate exceeds the highest level. ${ }^{4,5}$

The rate of CS is above the WHO determined mark for many countries, and it is increasing over the time. ${ }^{4}$ In United States (US) the rate of CS was 22.7 per cent in 1990, which increased to 27.5 per cent in 2003 and $30 \%$ in 2005. These levels and trends of CS rates are even higher in case of Latin America; it ranged from 16.8 per cent to as high as 40 per cent in these countries. Higher rates were observed in private hospitals than in the public ones. ${ }^{6}$ This rising trend in CS is not limited to USA or United Kingdom (UK). In Brazil, there are hospitals with $100 \%$ CS rate, health districts with $85 \%$ CS rate, and an entire state with a CS rate of $47.7 \% .^{7}$

The estimate for the CS rates in East Asia also showed that it is well above the 15 per cent mark. ${ }^{8}$ India is also not excluded from this trend. Though the estimates of CS rates in India was 7.1 per cent in the year 1998 and there was16.7 per cent change in the rates annually in India ${ }^{8}$ which was one of the highest among the countries. Though the constraint of data has masked the actual rates, but still the pace of change is very high. A five-year audit from a large teaching hospital of Kolkata, India showed a caesarean section rate of 49.9 per cent ${ }^{9}$ and another study in Madras showed an alarming caesarean section rate of 50 per cent. $^{10}$

This situation of overburdened caesarean rates needs special attention. The scenario of the states with respect to the CS and the complications that are responsible for the caesarean section is a matter that has to be given some insight into.

One possible contributor to this trend appears to be a developing tendency among physicians to promote the right of women to choose an elective CS which has triggered controversy. ${ }^{11}$ On the other hand, obstetricians' willingness to perform a CS for non-medical reasons differ largely. ${ }^{11}$ Most of the countries have no national policies concerning women's right to decide mode of delivery. Professional bodies also differ in their recommendations. The International Federation of Gynecologists and Obstetricians (FIGO) stated that: "surgical intervention without a medical rationale to fall outside best professional practice. Caesarean delivery should be undertaken only to enhance the well-being of mothers and babies and improve outcomes. ${ }^{12}$ At present, because hard evidence of net benefit does not exist, performing cesarean delivery for nonmedical reasons is not ethically justified. ${ }^{13}$ However, the guidelines from American College of Obstetricians and Gynecologists (ACOG) leave it more up to the belief of the physician involved "In the absence of significant data on the risks and benefits of cesarean delivery, if the physician believes that cesarean delivery promotes the overall health and welfare of the woman and her fetus more than vaginal birth, he or she is ethically justified in performing a cesarean delivery. ${ }^{13}$ Thus, it appears that standardized keys aiding obstetricians in decision making procedures concerning the CS practice have to be developed.

Sikkim is a small hilly state, located in the eastern Himalayas. It became the 22nd state of the Indian Union. Sikkim has a diverse geography, culture and ethnicity in contrast to other states of India. Sikkim is the only state in India with an ethnic Nepali majority. Increasing rates of cesarean section has also been observed in Sikkim along with other Indian states. Audit plays an important role in the analysis of changing trends in caesarean delivery rate the needs and benefits of such changes and to modify the obstetrician trend towards the use caesarean delivery. With this background we conducted this study to determine cesarean section rate in Sikkim and to analyze and compare the rate and indications for cesarean sections performed in Sikkim over a period of decade in the early 2000s as compared to early 2010s.

\section{METHODS}

All the women who were delivered by CS during the years 2001 and 2011 at the different hospitals of Sikkim were included for this survey. The original obstetrics records of all the patients were reviewed and in patients whose obstetrics records were incomplete their original obstetrics files were searched to gain correct information. The patients whose adequate information was not obtained were excluded from the study.

There were several reasons for choosing the two time periods. Firstly 2011 reflects the most current practice in different hospitals of Sikkim while 2001 reflects the general practice when the results of the term breech trial were just published. Secondly, it was noted that in most of the countries the cesarean section rate started to increase in late 1990s. It was postulated that a similar trend may be present in Sikkim also.

The indications for elective CS were a narrow pelvis, defined as a narrow pelvic outlet $<29.5 \mathrm{~cm}$ and/or an inter-spinal measure of $<8 \mathrm{~cm}$, or a narrow pelvic inlet with a conjugate vera of $<10 \mathrm{~cm}$. The group of disproportion included where the normal proportion between sizes of fetus to size of pelvis was disturbed. The term bad obstetric history $(\mathrm{BOH})$ included pregnant women where she had more than one previous obstetric disaster. The group of fetal factor included macrosomia, defined as an estimated fetal weight exceeding 4,500 gram according to ultrasonography examination, fetal 
diseases or malformations such as cardiac diseases, gastrochisis or hydrocephalus. The group maternal factor included subjects with intercurrent diseases such as diabetes mellitus, HIV infection or malignant diseases like carcinoma cervix. The group within maternal request included in which patient requested for CS for fear of childbirth or for any other reason without any co-existing medical or obstetric indication.

The indications for urgent and emergency CS were anticipated fetal compromise, defined as a pathological cardiotocography (CTG), umbilical cord prolapse, intrauterine fetal growth restriction less than -2 SD in combination with a pathological Doppler study or ultrasonographic signs of a twin-to-twin transfusion syndrome.

Failure to progress or nonprogress of labor was defined as prolonged labor or labor arrest. The group pathological fetal lie included cases with a breech presentation at term or diagnosed after labor onset, transverse and oblique lies. The group within maternal compromise included subjects with severe cardiovascular disease, maternal exhaustion or Rhesus immunization. The group prematurity included cases with premature rupture of fetal membranes or premature labor from $28+0$ to $36+6$ gestational weeks in combination with indication for early delivery. The category of "other" included uncommon indications which were not coded within the labeled category in this study.

The percentage of CS attributable to specific indications was computed for the year 2001 and 2011 respectively and cesarean section rate was calculated for both years.

\section{RESULTS}

In 2001, Sikkim had an institutional delivery rate of 6531 and a CS rate of $10.1 \%$. Elective CS constituted $23.9 \%$. The main indications for elective for an elective CS were previous cesarean $(24.1 \%)$ and cephalopelvic disproportion (16.5\%). Abnormal fetal lie and a previous bad mishap, each was responsible for seven percent of elective CS. Each group of maternal and fetal factor constituted five percent of CS while 3 cases were twin pregnancies where presenting fetus was other than cephalic. Information was not available in $15(9.5 \%)$ obstetric case records (Table 1). The main indications for an emergency CS were anticipated fetal distress $(23.8 \%)$, dystocia and disproportion detected in labor (19.2\%) and failure to progress of labor (12.5\%) (Table 2).

Table 1: Indications for elective cesarean section in the year 2001 and 2011.

\begin{tabular}{|c|c|c|c|c|}
\hline \multirow[t]{2}{*}{ Year } & \multicolumn{2}{|c|}{2001} & \multicolumn{2}{|c|}{2011} \\
\hline & $\mathbf{n}$ & $\%$ & $\mathbf{n}$ & $\%$ \\
\hline Total elective Caesarean sections & 158 & 23.9 & 533 & 40.7 \\
\hline \multicolumn{5}{|l|}{ Number and percentage by indications } \\
\hline Previous caesareans & 38 & 24.1 & 167 & 31.3 \\
\hline Disproportions (CPD) & 26 & 16.5 & 25 & 4.7 \\
\hline Bad obstetric history (BOH) & 11 & 7.0 & 15 & 2.8 \\
\hline Breech/Transverse lie & 11 & 7.0 & 25 & 4.7 \\
\hline Hypertensive disorders & 8 & 5.1 & 34 & 6.4 \\
\hline Antepartum haemorrhage (APH) & 7 & 4.4 & 13 & 2.4 \\
\hline Postdated with complications & 8 & 5.1 & 23 & 4.3 \\
\hline Fetal factor (e.g. macrosomia, malformation) & 8 & 5.1 & 12 & 2.3 \\
\hline Maternal factor (e.g. medical disease, HIV etc.) & 8 & 5.1 & 28 & 5.3 \\
\hline Multiple pregnancy & 3 & 1.9 & 4 & 0.8 \\
\hline Maternal request & 5 & 3.2 & 154 & 28.9 \\
\hline Others (e.g. fetal growth restriction) & 10 & 6.3 & 19 & 3.6 \\
\hline
\end{tabular}

In 2011, Sikkim had 6748 institutional delivery with a CS rate of $19.4 \%$. Information was not available in $3.4 \%$ cases. Elective CS constituted $40.7 \%$ of the CS. The main indications for an elective CS were previous CS in $31.3 \%$ and maternal request in $28.9 \%$. Cephalopelvic disproportion and pathological fetal lie each were responsible for $4.7 \%$ elective $\mathrm{CS}$ while hypertensive disorder constituted $6.4 \%$ of the elective CS (Table 1).
The top three indications for an urgent or emergency CS were anticipated fetal distress $(24.6 \%)$, failed induction $(14.8 \%)$ and previous CS in labor (11.3\%). Breech and abnormal lie presentation in labor and nonprogress of labour were responsible for $10.4 \%$ and $9.3 \%$ of emergency CS respectively. Twenty one women (2.7) demanded for cesarean in labor for psychosocial reasons (Table 2). 
Cases of anticipated fetal compromise were based on clinical and or a pathological CTG trace as no facility for biochemical test were available in none of the hospitals. Some cases were planned for elective cases attended emergency suit for prelabour rupture of membrane, uterine contractions or vaginal bleeding were categorized as urgent for this survey.

Table 2: Indications for urgent/emergency cesarean section in the year 2001 and 2011.

\begin{tabular}{|lllll|}
\hline Year & $\mathbf{2 0 0 1}$ & \multicolumn{2}{l|}{$\mathbf{2 0 1 1}$} & \\
\hline Total emergency Caesarean Sections & $\mathbf{n}$ & $\mathbf{\%}$ & $\mathbf{n}$ & $\mathbf{7}$ \\
\hline Number and percentage by indications & 504 & 76.1 & 777 & 59.3 \\
\hline Fetal distress & & & & \\
\hline Dystocia \& disproportion & 120 & 23.8 & 191 & 24.6 \\
\hline Non-progress of labour (NPOL) & 97 & 19.2 & 62 & 8.0 \\
\hline Antepartum haemorrhage (APH) & 63 & 12.5 & 72 & 9.3 \\
\hline Breech/Transverse lie & 23 & 4.6 & 13 & 1.7 \\
\hline Previous cesarean & 38 & 7.5 & 81 & 10.4 \\
\hline Postdated failed induction & 41 & 8.1 & 88 & 11.3 \\
\hline Prematurity & 29 & 5.8 & 115 & 14.8 \\
\hline Maternal compromise & 15 & 3.0 & 23 & 3.0 \\
\hline Hypertensive disorder & 19 & 3.8 & 25 & 3.2 \\
\hline Twins & 20 & 4.0 & 27 & 3.5 \\
\hline Patients request & 1 & 0.2 & 6 & 0.8 \\
\hline
\end{tabular}

\section{DISCUSSION}

Our survey showed that there was a drastic increase in the rate of cesarean deliveries in Sikkim province of India. The CS rate approximately doubled over a 10 year period, from $10.1 \%$ in 2001 to $19.4 \%$ in 2011 in Sikkim. This increase in rate of cesarean section has been a global phenomenon, the timing and rate of increase has differed from country to country and difference in rate persists. ${ }^{14}$

There are different reasons have been implicated for this rise of CS rate and include medical and psychosocial factors, such as malpractice concerns, reluctance to perform operative vaginal deliveries, concerns over aggressive oxytocin use, increased use of electronic fetal monitoring and most importantly, increasing number of patients with previous abdominal deliveries. ${ }^{15}$

In Asia survey the overall cesarean rate was $27.3 \%$. China had the highest overall cesarean rates $(46.2 \%)$ followed by Vietnam, Thailand and Sri Lanka; Cambodia had the lowest $(14.7 \%){ }^{16}$

Our study shows that our cesarean rate was comparable to that of the Asian countries and rate has doubled over a decade.

Our study showed that main indication for elective CS for both the years was previous cesarean section. Increasing rates of primary CS have led to an increased proportion of the obstetric population with a history of previous caesarean deliveries. The American College of Obstetricians and Gynecologists (ACOG) have endorsed the feasibility of vaginal birth after cesarean section (VBAC). ${ }^{17-19}$ The ACOG published a practice guideline summarizing the evidence supporting VBAC as the preferred method of delivery after previous $\mathrm{CS}^{20-21}$ The proportion of women who decline VBAC is, in turn, a significant determinant of overall rates of caesarean birth. $^{22}$ In a more litigation-conscious society, there is anxiety over induction of labour in patients with a previous CS. ${ }^{23}$ Moreover, patients correctly have the autonomy to decide what mode of delivery they want, and many prefer CS to be the safer choice.

One of the most significant finding of our study was that maternal request without any co-existing condition appeared to be second most common indication for elective cesarean section which constituted around $29 \%$ elective cesarean performed. In private hospitals the rate was even higher to the extent of $47 \%$. This suggests that that maternal request for CS contributed significantly to overall increase of CS rate in our study. CS performed because of fear of childbirth or on maternal request without any co-existing medical indication has been a matter of debate for ethical and medical reasons during more than a decade. ${ }^{1,24-27}$ This indication was reported in $1-48 \%$ of the CS in community obstetric units and in up to $60 \%$ in private clinics in previous studies. ${ }^{1}$ In our study maternal request for CS increased from $3.2 \%$ in 2001 to around $29 \%$ in the year 2011 which was quite alarming.

It is true that women now have greater influence over the management of their deliveries. A number of women opt for elective CS due to the fear of episiotomies, long 
painful labours, difficult instrumental deliveries, pelvic floor trauma and subsequent incontinence that are associated with vaginal births. ${ }^{28}$ One study has reported an association between fear of childbirth in late pregnancy and subsequent emergency $\mathrm{CS}^{29}$ In our study we found $2.7 \% \mathrm{CS}$ were performed in labor for fear of childbirth on maternal request. Negative expectations and fear of childbirth have been related to a history of depression, anxiety, lack of support, a previous negative birth experience and a previous urgent or emergency CS. ${ }^{30,31}$

On the other hand obstetricians' willingness to perform a CS for nonmedical reasons differs largely between regions and countries. The respect for woman's autonomy was the most quoted reason for an obstetrician to perform a CS on request without any medical indication in eight European countries in the period 2001-2002. ${ }^{11}$ Fear of childbirth and a previous CS were the most frequent reasons reported. A survey among Swedish obstetricians $79 \%$ was ready to perform a CS for maternal fear of childbirth, and $49 \%$ on maternal request without any co-existing medical indication. Concomitantly, physician's worry for negative consequences in connection to vaginal delivery that might be complicated was the strongest variable for the willingness to perform a CS for nonmedical reasons. Individual economical benefit has been reported as a confounding factor for the physician in regions with very high CS rates. $^{24,25}$

Nevertheless, fear of childbirth and the CS rates were reduced by $50-60 \%$ among pregnant women attending the antenatal classes and who were provided with psychological support when indicated. ${ }^{30-32}$ Importantly, 'one to one care' where one midwife cares for one mother during childbirth was associated with a more positive birth experience and a reduced risk for medical interventions as compared to routine care. ${ }^{30,33}$

Anticipated fetal distress remained the most common indication for emergency CS in both the study periods in our study with slight increase in 2011. Another important observation was significant increase rate of CS due to failed induction. This may be because of concern over aggressive use of induction, fear of litigation of the physician and women's psychosocial factors may influence early decision of failed induction.

Although this study drew on a state sample of trends of cesarean section, its principal limitation was the reliance on secondary data and the associated risk of misclassification bias. Classification of elective and emergency depends on reliable abstraction and coding at the institutional level and errors may be possible for many elective cesarean may have been coded as emergency for doing out of the hours. Another limitation was the arbitrary assignment of indications for cesarean. Some had multiple indications and authors assigned them to a most appropriate indication and some had inappropriate documentation of the indication. Inspite of these limitations, the authors believe that the information presented in this study are clinically relevant, has the advantage of being readily available from hospital-based aggregate information systems without the need for primary data collection.

The main purpose of this study was to find out the rate of cesarean sections in Sikkim and to present cesarean deliveries by indication. We noticed there was rising rate of cesarean section which contributed large number of women with previous cesarean sections. Another observation was increasing trend of cesarean section performed on maternal request. This is a worrying issue need to be addressed, since much effort is being directed at lowering cesarean rates globally. There is an urgent importance of development of standardized keys aiding an obstetrician in decision-making procedures concerning the indications for CS.

\section{CONCLUSION}

There was a significant increase in CS rates over the last decade in Sikkim. Increased rates of primary CS have led to an increased proportion of the obstetric population with a history of previous caesarean deliveries. Another significant contributory factor in increasing proportion of CS were cesarean sections on maternal request without any co-existing medical or obstetric indication which appeared as second most common indication for elective cesarean section in recent years.

Funding: No funding sources

Conflict of interest: None declared

Ethical approval: The study was approved by the Institutional Ethics Committee (IEC No: SMIMS/IEC/2012-Natl-SF2)

\section{REFERENCES}

1. Lavender T, Hofmeyr GJ, Neilson JP, Kingdon C, Cyte G. Cesarean section for non-medical reasons at term. Cochrane Database Syst Rev. 2006;3:CD004660.

2. Silver RM, Landon MB, Rouse DJ, Leveno KJ, Spong CY, Thom EA, et al. Maternal morbidity associated with multiple repeat cesarean deliveries. Obstet Gynecol. 2006;107:1226-32.

3. Levine EM, Ghai V, Barton JJ, Strom CM. Mode of delivery and the risk for respiratory diseases in newborns. Obstet Gynecol. 2001;97:439-42.

4. World Health Organization. Appropriate Technology for Birth. Lancet. 1985;326(8452):436-7.

5. World Health Organization. Indicators to Monitor Maternal Health Goals: Report of a Technical Working Group. WHO/F; 1994.

6. Belizan J, Althabe F, Barros F, Alexander S. Rate and Implications of Caesarean Sections in Latin America: Ecological Study. BMJ. 1999;319(7222):1397-00. 
7. Ratner D. Sobre a hipotese de establizacao das taxas de cesarean do Estado de Sao Paulo, Brasil. Rev Saude Publ. 1996;30:19-33.

8. Stanton Cynthia K, Holtz Sara.A. Levels and Trends in Caesarean Birth in the Developing World. Studies in Family Planning. 2006;37(1):41-8.

9. Pahari.K, A.Ghosh. Study of Pregnancy Outcome over a Period of Five Years in a Postgraduate Institute of West Bengal. J of Ind Med Assoc. 1997;95(6):172-4.

10. Sreevidya S, Sathiyasekaran BW. High caesarean rates in Madras (India): a population-based cross sectional study. $\mathrm{Br} \quad \mathrm{J}$ Obstet Gynecol. 2003;110(2):106-11.

11. Habiba M, Kaminski M, Da Fré M, Marsal K, Bleker O, Librero J, et al. Caesarean section on request: a comparison of obstetricians' attitudes in eight European countries. $\mathrm{Br} \mathrm{J}$ Obstet Gynecol. 2006;113:647-56.

12. Dickens BM, Cook RJ. The legal effects of fetal monitoring guidelines. Int $\mathrm{J}$ Gynaecol Obstet. 2010;108:170-3.

13. Lobel M, DeLuca RS. Psychosocial sequelae of cesarean delivery: Review and analysis of their causes and implications. Soc Sci Med. 2007; $64: 2272-84$

14. Thomas J, Paranjothy S. The Royal College of Obstetricians and Gynaecologists, Clinical Effectiveness Support Unit. The National Sentinel Caesarean Section Audit Report. London: RCOG press, 2001.

15. Caesarean childbirth: report of the NICHD task force on caesarean childbirth. Bethesda, Maryland: National Institute of Health, 1981. (DHHS publication No. [NIH] 82-2067.

16. Lumbiganon P, Laopaiboon M, Gülmezoglu AM, Souza JP, Taneepanichskul S, Pang R, et al. Method of delivery and pregnancy outcomes in Asia: the WHO global survey on maternal and perinatal health 2007-08. Lancet. 2010;375:490-9.

17. Bethesda, MD: National Institutes of Health. Caesarean childbirth 1981:1351-74. Report No. NIH 82-2067.

18. American College of Obstetricians and Gynaecologists. Maternal and fetal medicine. Guidelines for vaginal delivery after a previous caesarean birth. Washington, DC: ACOG; 1982.

19. American College of Obstetricians and Gynaecologists. Maternal and fetal medicine. Guidelines for vaginal delivery after a previous caesarean birth. Washington, DC: ACOG; 1998. ACOG committee opinion 64.
20. American College of Obstetricians and Gynaecologists. Vaginal delivery after a previous caesarean birth. Washington, DC: ACOG; 1995. ACOG committee opinion 143.

21. Enkin M. Labour and delivery after previous caesarean section. In: Enkin M, Keirse MJ, Renfew M, Neilson J, editors. A guide to effective care in pregnancy and childbirth. 2nd ed. New York: Oxford Univ Press, 1995.

22. Menacker F. Trends in caesarean rates for first births and repeat caesarean rates for low-risk women: United States, 1990-2003. Natl Vital Stat Rep 2005;54:1-8.

23. Lydon-Rochelle M, Holt VL, Easterling TR, Martin DP. Risk of uterine rupture during labour among women with a prior caesarean delivery. N Engl J Med. 2001;345:3-8.

24. Wagner M. Choosing cesarean section. Lancet. 2000;356:1677-80.

25. National Institute for Clinical Excellence. Why mothers die 2000-2002. Sixth report on confidential enquiries into maternal deaths in the United Kingdom. London: RCOG Press, 2004.

26. ACOG Committee opinion. Cesarean delivery on maternal request. Obstet Gynecol. 2007;110:150104.

27. Hildingson I, Rådestad I, Rubertsson C, Waldenström U. Few women wish to be delivered by cesarean section. $\mathrm{Br}$ J Obstet Gynecol. 2002;109:618-23.

28. Mould TA, Chong S, Spencer JA, Gallivan S. Women's involvement with the decision preceding their caesarean section and their degree of satisfaction. Br J Obstet Gynaecol. 1996;103:1074-7.

29. Ryding EL, Wijma B, Wijma K, Rydhström H. Fear of childbirth during pregnancy may increase the risk of emergency cesarean section. Acta Obstet Gynecol Scand. 1998;77:542-7.

30. Wolman WL, Chalmers B, Hofmeyr GJ, Nikoden VC. Postpartum depression and companionship in the clinical birth environment: a randomised controlled study. Am J Obstet Gynecol. 1993;168:1388-93.

31. Sjögren B, Thomassen P. Obstetric outcome of 100 women with severe anxiety over childbirth. Acta Obstet Gynecol Scand. 1997;76:948-52

32. Saisto T, Salmela-Aro K, Nurmi JE, Kononen T, Halmesmaki E. A randomised controlled trial of interventions in fear of childbirth. Obstet Gynecol. 2001;98:820-6.

33. Waldenström U, Turnbull D. Support during childbirth - one to one care. Br J Obstet Gynecol. 1998; 105:1160-70.

Cite this article as: Rahman $H$, Pradhan D. Rising trends and changed indications of caesarean sections in Sikkim, India: cause for concern? Int J Reprod Contracept Obstet Gynecol 2016;5:1851-6. 